\title{
New insights into irritable bowel syndrome: from pathophysiology to treatment
}

\author{
Alexandros Hadjivasilisa , Constantinos Tsioutisa , Adamantios Michalinos ${ }^{\mathrm{a}}$, Dimitrios Ntourakis ${ }^{\mathrm{a}}$, \\ Dimitrios K. Christodoulou ${ }^{b}$, Aris P. Agouridis ${ }^{a}$
}

European University Cyprus, Nicosia, Cyprus; University Hospital of Ioannina, School of Health Sciences, University

of Ioannina, Greece

\begin{abstract}
Irritable bowel syndrome (IBS) is the most common reason to visit a gastroenterologist. IBS was believed to be a functional disease, but many possible pathophysiologic mechanisms can now explain the symptoms. IBS patients are classified into subtypes according to their predominant bowel habit, based on the Rome IV criteria. These include diarrhea-predominant and constipation-predominant IBS, as well as the mixed type, a combination of the two. Usually, IBS treatment is based on the predominant symptoms, with many options for each subtype. A new promising treatment option, fecal microbiota transplantation, seems to have beneficial effects on IBS. However, treating the pathophysiological causative agent responsible for the symptoms is an emerging approach. Therefore, before the appropriate therapeutic option is chosen for treating IBS, a clinical evaluation of its pathophysiology should be performed.
\end{abstract}

Keywords Irritable bowel syndrome, pathophysiology, Rome IV criteria, treatment, fecal microbiota transplantation

Ann Gastroenterol 2019; 32 (6): 1-11

\section{Introduction}

Irritable bowel syndrome (IBS) is the most common reason to visit a gastroenterologist and the second most common reason, after common flu, to be absent from work [1]. It is estimated that around 15\% [2] of the general population is affected, with some studies even reporting up to $45 \%$ [3]. Usually, women are more commonly affected than men, in a ratio of $2: 1$, and the peak of the disease often starts in early adulthood [4]. In general, patients are evenly distributed among 3 subtypes (diarrheapredominant [IBS-D], constipation-predominant [IBS-C], or mixed [IBS-M]) but studies from specific geographical areas such as Europe found fewer patients with IBS-D than in the other 2

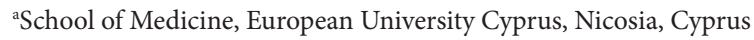
(Alexandros Hadjivasilis, Constantinos Tsioutis, Adamantios Michalinos, Dimitrios Ntourakis, Aris P. Agouridis); ${ }^{b}$ Department of Gastroenterology, University Hospital of Ioannina, School of Health Sciences, University of Ioannina, Greece (Dimitrios K. Christodoulou)

Conflict of Interest: None

Correspondence to: Aris P. Agouridis, MD, PhD, Diogenis Str 6 Nicosia CY, 2404 Cyprus, email: a.angouridis@euc.ac.cy

Received 2 July 2019; accepted 27 September 2019; published online 22 October 2019

DOI: https://doi.org/10.20524/aog.2019.0428 categories [5]. Women more commonly suffer from IBS-C and men from IBS-D [6]. It is believed that more than 20 billion dollars per year are spent on IBS treatment in the USA alone [7].

\section{Pathophysiology}

\section{Food intolerance}

One of the most common factors causing symptoms in IBS patients is food intolerance [8], with some studies reporting it in up to $89 \%$ of their patients [9]. Patients with IBS understand that specific types of food trigger their symptoms [10]. Usually, these include legumes, vegetables, lactose-containing foods, fatty foods, stone fruits, and artificial sweeteners [9]. In general, a category of foods that contain fermentable oligosaccharides, disaccharides, monosaccharides and polyols (FODMAPs) are known triggers that worsen IBS symptoms because of their osmotic and fermentation effects [11]. Small bowel distension was observed in magnetic resonance imaging studies after fructose was administered to patients with IBS [12], as a result of osmotic effects [11]. Interestingly, a meta-analysis found improvement in symptoms and $70 \%$ improvement in quality of life in patients after a low-FODMAP diet [13]. However, the problem with a low-FODMAP diet is that is very restrictive. Hence, monitoring by an experienced dietician is necessary to prevent any nutritional deficiencies and weight loss [14]. 
Other investigators reported an improvement in symptoms after gluten was eliminated from their patients' diet and relapse when it was reintroduced. Patients were not diagnosed with or suspect for celiac disease [15]. Another study reported that patients with IBS on a gluten diet had higher small bowel permeability, and the mRNA expression of tight junction proteins was considerably lower [16] than in non-gluten takers. Therefore, gluten might affect the pathogenesis of IBS by changing the epithelial barrier function, having a role in a pathway that we are not yet aware of.

\section{Enteric infection}

Patients sometimes complain about IBS symptoms after an infection. This is generally known as post-infectious IBS [8] and usually occurs after an acute bacterial, viral or protozoal gastroenteritis, when around $20 \%$ of patients will develop symptoms of IBS [17]. Risk factors include prolonged infection, prolonged fever, younger age, depression, and anxiety [1].

It is not yet clear whether or not IBS and post-infectious IBS share similar pathophysiology, since different characteristics of the 2 conditions have been observed by different investigators. Patients with IBS usually have a chronic relapsing disease, but in post-infectious IBS symptoms may resolve naturally in half of the patients within 6-8 years after the infection [18]. Furthermore, whereas several studies have found similarities in the microbiome between the two [10], other studies have reported completely different compositions [19].

The groups of pathogens that lead to IBS symptoms are still unknown, but colonic spirochetosis was linked previously with colonic eosinophilia, lymphoid follicles, and IBS-D [10,20]. Notably, in a study of almost 20,000 people [21] drinking water from a contaminated source, with pathogens such as Giardia lamblia, norovirus and Campylobacter jejuni, the investigators showed that the risk for IBS symptoms was greater in those with known anxiety, depression and younger age, enhancing the theories of a connection between brain and gut. Similar results were shown in a study of soldiers doing their military service [22].

\section{Inflammation - immunology}

Many patients who report IBS symptoms have inflammatory diseases [8]. Celiac disease [23], inflammatory bowel disease (IBD) [24], and severe acute gastroenteritis [25] are just some examples. Therefore, inflammation could be a predisposing factor for IBS symptoms, but the pathophysiology behind this still remains unclear. A probable explanation is that, after the inflammatory response, intestinal permeability is altered and infiltration with inflammatory cells occurs, which predisposes to localized edema and thence to the release of cytokines [26] that could probably, in combination with altered peristalsis and neuromuscular dysfunction [27], result in IBS symptoms.

Increased activation of the innate and adaptive immune systems was observed in the enteric mucosa of some IBS patients [28]. The immune system has the ability to distinguish harmless microorganisms from potentially pathogenic ones using recognition receptors, the toll-like receptors on neurons of the enteric nervous system (ENS), enteroendocrine and immune cells. Toll-like receptors contribute to an improvement in barrier function and to epithelial lumen repair, and are highly expressed in IBS patients [9].

Visceral hypersensitivity has also been associated with mucosal inflammation in a rat study [29] and with increased colonic and small bowel permeability in IBS-D patients [30]. Moreover, there are studies [31] that show high numbers of mast cells and increased concentrations of proinflammatory cytokines in IBS patients, in close proximity to the enteric nerve fibers, while other studies [32] have confirmed the mucosal inflammation from histology samples.

One study reported that patients with IBS have a $15-50 \%$ increase in their intestinal permeability [33]. This could be because patients with IBS seem to have increased amounts of interleukin-10, interleukin-6, tumor necrosis factor- $\alpha$, and other cytokines, and their concentration is associated with the frequency and severity of pain [34], but also with anxiety [35]. Additionally, alterations in tight junction proteins [36] and mast cell degranulation have been described in IBS patients, with tryptase release being a likely cause for the first [10]. Mucosal alterations were observed in a study [37] with IBS patients, after exposure to food antigens to which the individuals were intolerant. Those alterations included an increase in intraepithelial lymphocytes, widening of intervillous spaces, and epithelial gap formation [37].

\section{Gut-brain axis}

IBS is a good example of gut-brain axis dysregulation [26]. The gut-brain axis comprises the central nervous system (CNS), the hypothalamic pituitary axis (HPA), the autonomic nervous system and the ENS [9]. Triggers come from the gut via the vagus, the spinal and the enteric nerves [38]. The vagus nerve is the most important way of communication between the brain and the gut [38]. The HPA axis is also a very important component of this communication, because it regulates stress through production of corticosteroids, as well as aiding in digestion and the immune system [9]. CNS signals to the gut are transmitted by neuroendocrine neurotransmitters (serotonin, corticotropinreleasing hormone, cholecystokinin, and somatostatin), produced in the gut by immune and enterochromaffin cells (EC) to alter microbiota behavior [39]. This is possible because bacteria also have some neurotransmitter receptors and are influenced by those signals [38].

\section{Serotonin}

The ENS has been previously described as the second brain and contains 5 times the neurons of the spinal cord. Ninety percent of 5-hydroxy-tryptamine (5-HT) and 50\% of dopamine production is in the gastrointestinal tract, mainly by EC [9]. The 5-HT production is stimulated even more by spore-forming bacteria 
and changing immune responses, secretions and gastrointestinal motility [9]. This 5-HT stimulation is also influenced by microbiota, after exposure to short chain fatty acids (SCFA) [40] that come either from food and a FODMAP diet, or from SCFAproducing bacteria [9]. These SCFAs increase gut transit time via sympathetic nervous system and ENS stimulation [41] and could be possibly a causative factor for IBS symptoms.

The role of serotonin in the pathogenesis of IBS is also confirmed by studies [42] that examined different 5 -HT receptor drugs with positive effects on IBS symptoms. It has been observed that patients with post-infectious IBS have chronic increases in EC [43]; they also have increased serotonin after food intake, whereas IBS-C patients have reduced serotonin release [44]. Likewise, another study [45] found that in IBS-D patients the ratio of 5-hydroxyindoleacetic acid to 5-HT was reduced and concluded that those with IBS-D have lower serotonin reuptake while those with IBS- $C$ have lower serotonin release.

Serotonin metabolism can be influenced by genetic factors, many of which have been described in IBS patients [46]. In addition, in patients with IBS-C the long-long (LL) allele genotype appears to be a risk factor, at least for patients from East Asia [46]. In another study, the investigator found that IBS patients had much higher mucosal serotonin levels, associated with the number of mast cells and the severity of abdominal pain [47].

\section{Stress - depression}

Up to $75 \%$ of patients with IBS symptoms usually have coexisting anxiety or depression [10]. One study found that patients exposed to stressful events in their life tended to have more IBS symptoms, whereas those who had support showed fewer [1]. A large number of women with IBS describe prior abuse of one kind or another at some point in their life. A possible pathophysiological explanation for this could be the connection of the brain with the gut through the gut-brain axis, as explained above. One study of notable interest [48] reported that after rectal balloon distension in IBS patients, their brain regions associated with pain modulation and emotional arousal were highly engaged and activated. Furthermore, IBS patients have weaker inhibitory feedback mechanisms for emotional arousal and higher activity after visceral stimuli [48].

One interesting study [49] that compared anxiety and depression levels in IBS patients and healthy individuals found that the activity of the dorsolateral prefrontal cortex in IBS patients was dysregulated in behavioral selection duties. This indicates that patients with IBS can experience alterations in brain function, even without suffering depression or anxiety, that make them more vulnerable to stressful stimuli.

Norepinephrine production by stressful stimuli appears to enhance the growth of many intestinal pathogens, including Campylobacter jejuni [50], Escherichia coli (E. coli) and E. coli 0157:H7, with activation of the HPA axis [9]. It appears that this stress stimulation also affects the non-pathogenic bacteria, such as Lactobacilli and Bifidobacteria, promoting even more invasion from other potential pathogens [51].
Interestingly, IBS patients with children visit the pediatrician more often than non-IBS parents [1]. Newer epidemiological studies [52] have found out that, in almost half of the patients, intestinal symptoms appear first and mood disorders after, probably because the gut disturbances send signals to affect the brain. Likewise, in another study, psychiatric patients who also had IBS reported that they developed their psychiatric symptoms after they were diagnosed with IBS [53]. These extra-intestinal symptoms of IBS could again be explained in terms of the intestinal inflammation and cytokine mechanism altering the gut-brain axis [10,34], as described above. This is very interesting because it suggests the possibility of a newer approach to the treatment of mood disorders and psychiatric diseases in general [10].

\section{Y-Aminobutyric acid (GABA)}

GABA is an important inhibitory neurotransmitter that prevents abnormal firing of neurons in the CNS. Dysregulation of GABA leads to diseases such as epilepsy and anxiety disorders [9]. There are also thought to be GABA-b receptors involved in the gastrointestinal tract, affecting visceral sensation, pain and intestinal motility [9]. It is believed that the gut microbiota has the potential to produce GABA, with Bifidobacterium dentium and Lactobacillus brevis being the best producers, and that some foods produced by bacterial fermentation also contain GABA. This knowledge, though, has not yet been applied in clinical practice [54].

\section{Genetics}

IBS is more common in monozygotic twins than in dizygotic, suggesting a possible genetic background for the disease [55]. This is plausible, since a specific mutation was found to be common in $2 \%$ of IBS patients in one study and the majority of those had IBS-C [56]. 5CN5A is a sodium channel gene mutation correlated with congenital prolonged QT interval and abdominal pain [57]. It was reported that an IBS-C patient had normalization of his stool habits after using mexiletine, an antiarrhythmic drug [56], suggesting possible new therapeutic approaches in such individuals. Congenital sucrose isomaltase deficiency has also been observed in many families with IBS, possibly affecting the disease in a yet unknown manner [58].

\section{Bile acid metabolism}

Idiopathic bile acid diarrhea is estimated to affect up to $20 \%$ of IBS-D patients [59], while IBS-C patients have altered bile acid metabolism [60]. Bile acids are produced in the liver and are mostly in a conjugated state with other proteins [61]. De-conjugation occurs in the intestine and is caused by the bacteria there. Consequently, there is an increase in chloride secretion and a decrease in sodium absorption. Therefore, if the intestine is exposed to large amounts of bile acids, diarrhea may result. Conversely, if there is an insufficient amount of bile acids 
in the feces, constipation may occur [9]. The most important step in the negative feedback mechanism is the inhibition of bile acid formation by fibroblast growth factor 19 [60]. Fecal bile acids were observed to have higher levels in IBS-D and lower levels in IBS-C patients; their concentration was associated with stool number and shape [62]. In addition, IBS-D patients have higher levels of 7a-hydroxy-4-cholesten-3-one (C4), a bile acid synthesis marker [63], increased fecal bile acid, with greater colonic transit and intestinal and colonic permeability [64]. Moreover, intestinal dysbiosis was observed in patients with higher amounts of fecal bile acids, particularly an increase of E. coli and reduction in Bifidobacteria [65]. The association between bile acid metabolism and IBS can also be confirmed by the improvement of IBS symptoms seen in patients who took the bile acid sequestrant colestipol [59].

\section{Microbiota}

As many as a few trillion microbes live in our bowel and make up more than 1000 different species, outnumbering the number of the cells in our body by 10 times [66]. The 4 most important bacterial phyla in microbiota are Firmicutes (including Lactobacillus), Actinobacteria (including Bifidobacteria), Bacteroidetes (including B. fragilis) and Proteobacteria (including E. coli, Yersinia, Shigella, Salmonella and many more), but it also contains viruses, fungi and protozoa [67]. Some types of bacteria, such as Lactobacilli, Bifidobacteria and E. coli, have the ability to interfere with the immune system, causing anti-inflammatory responses [68]. Furthermore, microbiota is believed to protect bowel barrier function and ensure homeostasis of the gut-brain axis [69], commonly described as pathophysiological pathways for IBS.

It is assumed that IBS patients have altered microbiota in their intestines [70]. Observations from a study in 110 IBS patients show that patients with IBS have different intestinal microbiota, with lower microbial variety and lower numbers of Methanobacteriales and Prevotella species [71]. Lactobacillus and Bacteroides species, known beneficial bacteria, are also depleted, while the numbers of pathogenic bacteria, such as Streptococcus $s p p$., are increased [72]. In a study of IBS patients with abdominal pain, the investigators observed that patients with pain had 5 times smaller amounts of Bifidobacteria in their intestines [73].

One of the most common symptoms in IBS is abdominal distension [74], and gas-producing bacteria may be responsible for this. It occurs because gas distends the bowel, not allowing the diaphragm to completely relax, which in turn pushes the abdomen outwards, leading to profound abdominal distension [75].

\section{Presentation}

Patients with IBS are classified into subtypes according to their predominant bowel habit (Table 1). These include IBS-D, IBS-C and mixed IBS (IBS-M), a combination of the previous two. Usually, IBS-D and IBS-C have similar prevalence [76]. Common signs and symptoms of IBS are abdominal pain, bloating, straining during defecation, sensation of incomplete evacuation, mucus with stools, urgency [77], postprandial symptoms [78], depression, and anxiety [79].

\section{Differential diagnosis}

Given the lack of any diagnostic marker or examination, IBS can be presented or misdiagnosed as another disease with similar signs or symptoms [81]. The differential diagnosis includes many diseases, not only of the gastrointestinal tract, but also from extraintestinal causes. Diseases that commonly present with diarrhea and should be excluded first are microscopic colitis [82], IBD [83], celiac disease [84], infections [85], hyperthyroidism [86], carbohydrate malabsorption [87], and bile acid diarrhea [88]. On the other hand, disorders that present with constipation and should be excluded are colorectal cancer or anal malignancy that obstructs the lumen [89], dyssynergic defecation [90], and hypothyroidism [86]. Other reasons for abdominal pain should also be excluded in patients with IBS. Endometriosis, diverticulitis, pelvic inflammatory disease, and ovarian cancer are just some examples of diseases that could possibly present with similar abdominal pain [86].

\section{Workup}

History and physical examination are both very important in the evaluation of patients with IBS [91]. Usually, if no alarming signs or symptoms are present, nor other risk factors for organic disease, the diagnosis of IBS can be made with confidence, especially for IBS-C [86]. Alarming signs and symptoms should be excluded and if present further investigated (Table 2). These include blood in stools, more than $10 \%$ unintentional weight

Table 1 Subtypes of irritable bowel syndrome according to Rome IV criteria

\begin{tabular}{ll}
\hline Subtype & Characteristics \\
\hline Diarrhea-predominant & $>25 \%$ loose stools, $<25 \%$ hard stools \\
Constipation-predominant & $>25 \%$ hard stools, $<25 \%$ loose stools \\
Mixed-type & $>25 \%$ loose stools, $>25 \%$ hard stools \\
\hline
\end{tabular}

Table 2 Alarming features

Alarming features

Blood in stools

More than $10 \%$ unintentional weight loss

Disease that wakes the patient up during the night

Fever

New onset of signs and symptoms after the $50^{\text {th }}$ year of age

Family history of colorectal cancer, inflammatory bowel disease, or celiac disease 
loss, disease that wakes the patient up during the night, fever, new onset of signs and symptoms after the $50^{\text {th }}$ year of age, and a family history of colorectal cancer, IBD or celiac disease [82]. During physical examination, perianal area inspection for fissures or fistulas should be performed [77] as well as a digital rectal exam to check for any anal pathology [90].

A full blood count and a C-reactive protein tests are usually enough to reassure the patient that no organic disease exists, provided that no other risk factors or alarming signs and symptoms are present [77]. Otherwise, anything suspicious should be investigated. Investigations include serological tests for celiac disease in IBS-D patients [92], thyroid hormone evaluation, fecal calprotectin for IBD, and stool analysis for infectious microorganisms in IBS-D patients [85].

Invasive procedures, such as colonoscopy and upper gastrointestinal endoscopy, should only be performed if there is a specific indication for them, like blood in stools, increased inflammatory markers, or according to the colorectal cancer screening guidelines in each country [93]. IBS-D patients should be evaluated for microscopic colitis with biopsies during colonoscopy, especially if they are women aged more than 50 years [82]. They should also be tested for bile acid-induced diarrhea using a 75-homocholic acid taurine test or serum C4 levels, but if those are not available a simple bile acid binding agent will help to diagnose patients with such a disease [88]. Likewise, carbohydrate malabsorption should also be excluded by lactose breath test or by excluding suspected foods or drinks that trigger symptoms [94]. Last but not least, celiac disease with duodenal biopsies should be excluded if the patient's history or serological testing point in this direction [84].

\section{Diagnosis: Rome IV criteria}

The first attempt to produce IBS diagnostic criteria was back in 1978: the so-called Manning criteria [95], which include common symptoms for IBS that do not exist so often in other organic diseases (Table 3). A few years later, the Rome foundation developed the Rome I criteria, the first version of the Rome IV criteria (Table 4) currently used to diagnose patients with IBS [80]-at least for research purposes, since they are complex and difficult to remember in everyday practice [96]. Rome IV criteria replaced their previous version, Rome III criteria (Table 5), in 2016 because of their uncertainties and because they had not been adequately validated [97]. The sensitivity of Rome III criteria was $73 \%$ and their specificity 93\%, whereas Rome IV criteria have $62 \%$ sensitivity and $97 \%$ specificity [96]. Accordingly, several studies found a positive likelihood ratio of 21 for the Rome IV criteria, but only 10 for Rome III, where the higher the ratio, the more likely the finding is associated with a true disease [96]. The main difference between the 2 is that abdominal discomfort, a vague term, was removed from the Rome IV criteria and now only patients with abdominal pain can be diagnosed with IBS [98]. Moreover, with the Rome III criteria pain was relieved after defecation, but now, with the Rome IV criteria, this has been altered to refer to pain "changes" after defecation, because there are also patients who experience more pain after defecation [91]. In addition, in the Rome IV criteria abdominal pain has to be present at least 1 day per week for 3 months, whereas in Rome III this was at least 3 days per month [96]. Equally important is that the subtypes of the disease (IBS-D, IBS-C, IBS-M, and IBS-U), using the Rome IV criteria, are categorized based on the number of abnormal bowel movements, rather than on all bowel movements as with the Rome III criteria [96]. Lastly, IBS is now considered a gutbrain axis disorder and not a functional disease, removing the stigmatization from IBS patients [91].

Besides IBS, the Rome IV criteria include many functional disorders. Some examples are functional diarrhea, functional constipation, functional dyspepsia, functional bloating, functional abdominal pain, and unspecified functional bowel disorder [98]. In addition, the presence of other functional disorders, including fibromyalgia, chronic fatigue, and other gastrointestinal or extraintestinal functional disorders, makes IBS most likely as a diagnosis [99].

\section{Treatment}

The treatment for IBS is usually based on the predominant symptoms. However, treating the pathophysiological

Table 3 Manning criteria

Manning criteria (at least 3 of the following)

\begin{tabular}{l} 
Abdominal pain gets better after defecation \\
Pain associated with looser stools \\
Pain associated with more frequent stools \\
Feeling of incomplete evacuation \\
Mucus in stools \\
Abdominal distention \\
\hline
\end{tabular}

Table 4 Rome IV criteria

\begin{tabular}{l} 
Rome IV criteria \\
\hline Recurrent abdominal pain, at least 1 day per week for the last 3 \\
months associated with 2 or more of the following: \\
Defecation \\
Change in stool frequency \\
Change in stool appearance (form)
\end{tabular}

Table 5 Rome III criteria

Rome III criteria

Recurrent abdominal pain or discomfort at least 3 days per month for the past 3 months associated with 2 or more of the following:

Improvement with defecation

Onset associated with change in frequency of stool

Onset associated with a change in stool appearance (form) 
causative agent responsible for the symptoms is an emerging approach [91]. An acceptable initial therapy, especially for patients with mild disease, is lifestyle modification and education. This starts with removing gas-producing foods and by following a low-FODMAP diet (Table 6). If this is helpful, then reintroduction of foods, one at a time, is encouraged. Otherwise, these specific foods should be avoided in the long term [100]. A low-FODMAP diet has been shown to help patients in relieving abdominal pain, bloating, and stool consistency [101]. Lactose avoidance is also an option in some patients, both those with and without lactose intolerance, since it is possible that an ingredient in milk other than lactose triggers symptoms [101]. Likewise, it was reported that a gluten diet also causes IBS symptoms in non-celiac disease patients, but this may be because of fructans, also found in wheat, and not gluten. Nevertheless, in the latest guidelines for IBS from the American College of Gastroenterology (ACG), a gluten- free diet is not recommended, because the studies suggesting it have not shown statistically significant results [102].

Treatment for IBS-C should be targeted to alleviate constipation (Table 7). Increased fiber consumption is recommended, and soluble fibers such as psyllium are preferred to insoluble fibers such as bran as a first step [103]. An initial first pharmacological treatment could include osmotic laxatives, such as polyethylene glycol, but it may not help with pain [104]. Thus, in their latest guidelines the ACG no longer recommends it, since the evidence to support its use is not statistically significant [102]. Therefore, linaclotide or lubiprostone can be used instead, since they improve colonic transit time and abdominal pain [105]. Moreover, plecanatide, used for chronic idiopathic constipation, is a recent promising option for IBS-C that has been shown to improve IBS symptoms in general [102]. Last but not least, lactulose, also an osmotic laxative, should be avoided because it produces a lot of gas and results in bloating [80].

Table 6 Examples of diet with high and low fermentable oligosaccharides, disaccharides, monosaccharides and polyols (FODMAPs)

\begin{tabular}{lll}
\hline Type of food & High FODMAP & Low FODMAP \\
\hline Vegetables & $\begin{array}{l}\text { Onion, garlic, leek, asparagus, artichoke, } \\
\text { cauliflower, mushrooms, green peas }\end{array}$ & $\begin{array}{l}\text { Carrots, eggplants, bell peppers, lettuce, } \\
\text { cucumber, tomato, potato, zucchini }\end{array}$ \\
\hline Fruits & Watermelon, apples, cherries, mango \\
Dairy & $\begin{array}{l}\text { Cow's milk, evaporated milk, soy milk, } \\
\text { cottage cheese, ice cream }\end{array}$ & Grapes, kiwi, oranges, strawberries, pineapple \\
Protein & Legumes, processed meat, marinated meats & $\begin{array}{l}\text { Almond milk, coconut milk, hard cheese, } \\
\text { butter, lactose free }\end{array}$ \\
Cereals & Wheat, rye, barley, spelt & Eggs, tofu, non-marinated meats, fish, chicken \\
\hline Sugars & High fructose, honey & Oats, quinoa, corn, sourdough bread \\
\hline Nuts and seeds & Cashews, pistachios & Maple syrup, table sugar \\
\hline
\end{tabular}

Table 7 Drugs for irritable bowel syndrome

\begin{tabular}{|c|c|c|}
\hline Drugs & Mode of action & Side effects \\
\hline \multicolumn{3}{|l|}{ Drugs for IBS-C } \\
\hline $\begin{array}{l}\text { Linaclotide } \\
\text { Lubiprostone } \\
\text { Plecanatide [102] }\end{array}$ & $\begin{array}{l}\text { Guanylate cyclase-C receptor agonist [1] } \\
\text { Type } 2 \text { chloride channel activator [1] } \\
\text { Guanylate cyclase-C receptor agonist }\end{array}$ & $\begin{array}{l}\text { Diarrhea, headache [26] } \\
\text { Nausea, diarrhea [26] } \\
\text { Diarrhea }\end{array}$ \\
\hline \multicolumn{3}{|l|}{ Drugs for IBS-D } \\
\hline $\begin{array}{l}\text { Cholestyramine [1] } \\
\text { Eluxadoline [91] } \\
\text { Alosetron } \\
\text { Rifaximin }\end{array}$ & $\begin{array}{l}\text { Bile acid sequestrant } \\
\mu \text { and } \kappa \text { opioid receptor agonist and } \delta \text {-receptor } \\
\text { antagonist } \\
\text { Selective } 5 \text {-HT3 receptor antagonist [77] } \\
\text { Modulation of gut microbiota [91] }\end{array}$ & $\begin{array}{l}\text { Constipation } \\
\text { Constipation, pancreatitis } \\
\text { Constipation, ischemic colitis [86] } \\
\text { Headache, nausea, diarrhea [26] }\end{array}$ \\
\hline \multicolumn{3}{|l|}{ Drugs for abdominal pain } \\
\hline Dicyclomine or hyoscyamine & Reduce smooth muscle contractions [1] & $\begin{array}{l}\text { Constipation, dry mouth, dry } \\
\text { eyes [26] }\end{array}$ \\
\hline Peppermint oil & Relaxes smooth muscles [91] & Heartburn, dyspepsia ${ }^{[26]}$ \\
\hline \multicolumn{3}{|l|}{ More pharmacological options } \\
\hline Tricyclic antidepressants & $\begin{array}{l}\text { Inhibition of active neuronal uptake of the } \\
\text { biogenic amines (5-HT and norepinephrine) [77] }\end{array}$ & $\begin{array}{l}\text { Arrhythmias, sexual dysfunction, } \\
\text { sedation, orthostatic hypotension [26] }\end{array}$ \\
\hline SSRIs & Serotonin reuptake inhibitors & Dry mouth, drowsiness [77] \\
\hline
\end{tabular}

IBS-C, constipation-predominant irritable bowel syndrome; IBS-D, diarrhea-predominant irritable bowel syndrome; 5-HT, 5-hydroxy-tryptamine; SSRIs, selective serotonin reuptake inhibitors 
Likewise, treatment for IBS-D should be targeted to alleviate diarrhea (Table 7). Loperamide can help with diarrhea by inhibiting peristalsis and increasing colonic transit time, but again it may not help with abdominal pain [106]. It is not recommended by thelatest ACG guidelines because its efficacy in IBS-D patients was not statistically significant [102]. Therefore, cholestyramine, a bile acid sequestrant, could be tried as first-line treatment if bile acid diarrhea is suspected [107], or eluxadoline, a $\mu$ and $\kappa$ opioid receptor agonist and a $\delta$-receptor antagonist in the ENS that has been proven to improve global symptoms in IBS-D [102]. However, eluxadoline increases the risk of pancreatitis, so it should be used with caution in patients with increased risk factors for that disease [102]. Alosetron, a 5-HT type 3 antagonist, appears to improve abdominal pain, but should be used with caution only in women with severe IBS-D symptoms [108] because of serious side-effects, including ischemic colitis [109]. Last but not least, rifaximin, a poorly absorbed drug used for traveler's diarrhea, has been shown to improve symptoms in general and to help patients with IBS-D. However, its effect seems to diminish over time, so treatment should be repeated if effective [110].

Additionally, regardless of the predominant type, every patient with IBS suffers from abdominal pain, according to the Rome IV criteria [98]. Antispasmodics on an as-needed basis are the treatment of choice to relieve pain; they work by reducing smooth muscle contractions and possibly by altering visceral hypersensitivity (Table 7). However, they should be used with caution in IBS-C because of their anticholinergic effects [111]. Examples of such drugs are dicyclomine and hyoscyamine, but peppermint oil can also be included among the available treatment options (Table 7). Peppermint oil, which has antispasmodic effects, has been shown to provide symptomatic relief in abdominal pain but was associated with heartburn [112].

Tricyclic antidepressants are the category of antidepressants that have been tested the most for IBS, and many studies found that they relieve abdominal pain and diarrhea symptoms, and improve slow colonic transit times (Table 7). However, their use is limited by their numerous side effects, which include drowsiness, dry mouth, fatigue, and constipation [77]. On the other hand, serotonin reuptake inhibitors have a safer profile and improve symptoms in general compared with placebo [112]. Interestingly, cognitive behavioral therapies, hypnotherapy and psychotherapy appear to be helpful in reducing global symptoms [113], most probably because of the gut-brain connection. Likewise, regular mild exercise appears to reduce bloating and gas production [114].

In addition, 5-aminosalicylates have been used in randomized controlled trials in patients with IBS because of the theory about low-grade intestinal inflammation; however, they are not yet recommended, despite the promising results that these studies found [102].

Last but not least, probiotics seem to be helpful in reducing symptoms, but it is not yet clear which strains of bacteria are the most effective [115]. It is believed that they improve symptoms like abdominal pain and bloating by altering the intestinal microbiota, which may play an important role in the pathogenesis of IBS [116]. As a matter of fact, Bifidobacterium infantis 35624 has been found beneficial in improving global symptoms and in normalizing bowel movements in all IBS subtypes. Likewise, Bifidobacterium lactis DN-173010 and VSL\#3 probiotics have been proven effective in treating flatulence, distention and bloating [86]. On the other hand, prebiotics and synbiotics are not recommended [102].

\section{Fecal microbiota transplantation (FMT)}

An altered microbiota is believed to be a main pathophysiological factor behind IBS. Patients with IBS have been found to have different microbiota composition from healthy patients [117], but it is not yet clear which bacteria species are the ones responsible for the symptoms [118]. FMT is a relatively new and promising procedure for the treatment of IBS. It has been well studied in patients with C. difficile infection and is already considered as an effective option [119]. Over the last few years, FMT has been considered as a potential therapeutic option in other diseases apart from C. difficile infection. These include inflammatory bowel diseases, metabolic syndrome [120], colonization of the gastrointestinal tract by pathogenic and multi-resistant microorganisms, type 2 diabetes mellitus, obesity [121], chronic stress [122], the autistic spectrum of disorders, and depression [123].

Before the procedure, donors should be interviewed regarding their medical history and lifestyle. Specific attention should be paid to infectious diseases, because there is a high possibility that any such will also pass to the recipient, but also to metabolic and neurological diseases [124]. The relation of the donor with the recipient should also be determined, since IBS pathogenesis also has a genetic component and a firstdegree relative might have a similar microbiota. However, one study found that this might not be significant, reporting similar outcomes from first-degree relatives and unrelated donors [125].

For the procedure, at least $30 \mathrm{~g}$ of stool should be used [126] and the effect is the same whether fresh or frozen stools are used [127]. The stools are then introduced into the patient's intestines in the form of a suspension, using a colonoscope, enema, nasoenteric tube or gastroscope. All these methods have similar outcomes [125].

FMT appears to be effective based on already published studies $[128,129]$. Those studies reported that the response to the treatment was successful and patients had significant improvement in abdominal pain, bloating and flatulence. Symptom relief was from $70-85 \%$ in the first 3 months and from $45-60 \%$ in 6 months, suggesting that the procedure might need to be repeated again in the future.

\section{Concluding remarks}

IBS is a very common disease. However, its pathophysiology is still not fully understood. Usually, treatment for IBS is based on the predominant symptoms, with many options for each 
subtype. FMT is a promising new option for patients with IBS and seems to have a beneficial effect. However, treating the pathophysiological causative agent responsible for the symptoms is an emerging approach. Hence, before choosing the appropriate therapeutic option for treating IBS, clinical judgement on its pathophysiology should be made.

\section{References}

1. Defrees DN, Bailey J. Irritable bowel syndrome: epidemiology, pathophysiology, diagnosis, and treatment. Prim Care 2017;44:655-671.

2. Drossman DA, Camilleri M, Mayer EA, Whitehead WE. AGA technical review on irritable bowel syndrome. Gastroenterology 2002;123:2108-2131.

3. Lovell RM, Ford AC. Global prevalence of and risk factors for irritable bowel syndrome: a meta-analysis. Clin Gastroenterol Hepatol 2012;10:712-721.

4. Mayer EA. Clinical practice. Irritable bowel syndrome. $N$ Engl J Med 2008;358:1692-1699.

5. Guilera M, Balboa A, Mearin F. Bowel habit subtypes and temporal patterns in irritable bowel syndrome: systematic review. Am J Gastroenterol 2005;100:1174-1184.

6. Lovell RM, Ford AC. Effect of gender on prevalence of irritable bowel syndrome in the community: systematic review and metaanalysis. Am J Gastroenterol 2012;107:991-1000.

7. Everhart JE, Ruhl CE. Burden of digestive diseases in the United States part II: lower gastrointestinal diseases. Gastroenterology 2009;136:741-754.

8. Chey WD, Kurlander J, Eswaran S. Irritable bowel syndrome: a clinical review. JAMA 2015;313:949-58.

9. Raskov H, Burcharth J, Pommergaard HC, Rosenberg J. Irritable bowel syndrome, the microbiota and the gut-brain axis. Gut Microbes 2016;7:365-383.

10. Holtmann GJ, Ford AC, Talley NJ. Pathophysiology of irritable bowel syndrome. Lancet Gastroenterol Hepatol 2016;1:133-146.

11. Shepherd SJ, Parker FC, Muir JG, Gibson PR. Dietary triggers of abdominal symptoms in patients with irritable bowel syndrome: randomized placebo-controlled evidence. Clin Gastroenterol Hepatol 2008;6:765-771.

12. Murray K, Wilkinson-Smith V, Hoad C, et al. Differential effects of FODMAPs (fermentable oligo-, di-, mono-saccharides and polyols) on small and large intestinal contents in healthy subjects shown by MRI. Am J Gastroenterol 2014;109:110-119.

13. Marsh A, Eslick EM, Eslick GD. Does a diet low in FODMAPs reduce symptoms associated with functional gastrointestinal disorders? A comprehensive systematic review and meta-analysis. Eur J Nutr 2016;55:897-906.

14. Molina-Infante J, Serra J, Fernandez-Bañares F, Mearin F. The lowFODMAP diet for irritable bowel syndrome: lights and shadows. Gastroenterol Hepatol 2016;39:55-65.

15. Elli L, Tomba C, Branchi F, et al. Evidence for the presence of nonceliac gluten sensitivity in patients with functional gastrointestinal symptoms: results from a multicenter randomized double-blind placebo-controlled gluten challenge. Nutrients 2016;8:84.

16. Vazquez-Roque MI, Camilleri M, Smyrk T, et al. A controlled trial of gluten-free diet in patients with irritable bowel syndromediarrhea: effects on bowel frequency and intestinal function. Gastroenterology 2013;144:903-911.

17. Keely S, Walker MM, Marks E, Talley NJ. Immune dysregulation in the functional gastrointestinal disorders. Eur J Clin Invest 2015;45:1350-1359.
18. Spiller R, Lam C. An update on post-infectious irritable bowel syndrome: role of genetics, immune activation, serotonin and altered microbiome. J Neurogastroenterol Motil 2012;18:258-268.

19. Sundin J, Rangel I, Fuentes S, et al. Altered faecal and mucosal microbial composition in post-infectious irritable bowel syndrome patients correlates with mucosal lymphocyte phenotypes and psychological distress. Aliment Pharmacol Ther 2015;41:342-351.

20. Walker MM, Talley NJ, Inganäs L, et al. Colonic spirochetosis is associated with colonic eosinophilia and irritable bowel syndrome in a general population in Sweden. Hum Pathol 2015;46:277-283.

21. Wouters MM, Van Wanrooy S, Nguyen A, et al. Psychological comorbidity increases the risk for postinfectious IBS partly by enhanced susceptibility to develop infectious gastroenteritis. Gut 2016;65:1279-1288.

22. Riddle MS, Welsh M, Porter CK, et al. The epidemiology of irritable bowel syndrome in the US military: findings from the millennium cohort study. Am J Gastroenterol 2016;111:93-104.

23. Sainsbury A, Sanders DS, Ford AC. Prevalence of irritable bowel syndrome-type symptoms in patients with celiac disease: a metaanalysis. Clin Gastroenterol Hepatol 2013;11:359-365.e1.

24. Halpin SJ, Ford AC. Prevalence of symptoms meeting criteria for irritable bowel syndrome in inflammatory bowel disease: systematic review and meta-analysis. Am J Gastroenterol 2012;107:1474-1482.

25. Dai C, Jiang M. The incidence and risk factors of post-infectious irritable bowel syndrome: a meta-analysis. Hepatogastroenterology 2012;59:67-72.

26. Ford AC, Lacy BE, Talley NJ. Irritable bowel syndrome. N Engl J Med 2017;376:2566-2578.

27. Wouters MM, Vicario M, Santos J. The role of mast cells in functional GI disorders. Gut 2016;65:155-168.

28. Ohman L, Simrén M. Pathogenesis of IBS: role of inflammation, immunity and neuroimmune interactions. Nat Rev Gastroenterol Hepatol 2010;7:163-173.

29. Adam B, Liebregts T, Gschossmann JM, et al. Severity of mucosal inflammation as a predictor for alterations of visceral sensory function in a rat model. Pain 2006;123:179-186.

30. Matricon J, Meleine M, Gelot A, et al. Review article: associations between immune activation, intestinal permeability and the irritable bowel syndrome. Aliment Pharmacol Ther 2012;36:1009-1031.

31. Mearin F, Perelló A, Balboa A, et al. Pathogenic mechanisms of postinfectious functional gastrointestinal disorders: results 3 years after gastroenteritis. Scand J Gastroenterol 2009;44:1173-1185.

32. Coëffier M, Gloro R, Boukhettala N, et al. Increased proteasomemediated degradation of occludin in irritable bowel syndrome. Am J Gastroenterol 2010;105:1181-1188.

33. BischoffSC, Barbara G, Buurman W, et al. Intestinal permeability-a new target for disease prevention and therapy. BMC Gastroenterol 2014;14:189.

34. Hughes PA, Harrington AM, Castro J, et al. Sensory neuro-immune interactions differ between irritable bowel syndrome subtypes. Gut 2013;62:1456-1465.

35. Liebregts T, Adam B, Bredack C, et al. Immune activation in patients with irritable bowel syndrome. Gastroenterology 2007;132:913-920.

36. Bertiaux-Vandaële N, Youmba SB, Belmonte L, et al. The expression and the cellular distribution of the tight junction proteins are altered in irritable bowel syndrome patients with differences according to the disease subtype. Am J Gastroenterol 2011;106:2165-2173.

37. Fritscher-Ravens A, Schuppan D, Ellrichmann M, et al. Confocal endomicroscopy shows food-associated changes in the intestinal mucosa of patients with irritable bowel syndrome. Gastroenterology 2014;147:1012-1020.e4.

38. Carabotti M, Scirocco A, Maselli MA, Severi C. The gut-brain axis: interactions between enteric microbiota, central and enteric nervous systems. Ann Gastroenterol 2015;28:203-209.

39. Bravo JA, Julio-Pieper M, Forsythe P, et al. Communication 
between gastrointestinal bacteria and the nervous system. Curr Opin Pharmacol 2012;12:667-672.

40. Reigstad CS, Salmonson CE, Rainey JF $3^{\text {rd }}$, et al. Gut microbes promote colonic serotonin production through an effect of short-chain fatty acids on enterochromaffin cells. FASEB $J$ 2015;29:1395-1403.

41. Di Mauro A, Neu J, Riezzo G, et al. Gastrointestinal function development and microbiota. Ital J Pediatr 2013;39:15.

42. Gershon MD, Tack J. The serotonin signaling system: from basic understanding to drug development for functional GI disorders. Gastroenterology 2007;132:397-414.

43. Dunlop SP, Jenkins D, Neal KR, Spiller RC. Relative importance of enterochromaffin cell hyperplasia, anxiety, and depression in postinfectious IBS. Gastroenterology 2003;125:1651-1659.

44. Dunlop SP, Coleman NS, Blackshaw E, et al. Abnormalities of 5-hydroxytryptamine metabolism in irritable bowel syndrome. Clin Gastroenterol Hepatol 2005;3:349-357.

45. Atkinson W, Lockhart S, Whorwell PJ, Keevil B, Houghton LA. Altered 5-hydroxytryptamine signaling in patients with constipation- and diarrhea-predominant irritable bowel syndrome. Gastroenterology 2006;130:34-43.

46. Zhang ZF, Duan ZJ, Wang LX, Yang D, Zhao G, Zhang L. The serotonin transporter gene polymorphism (5-HTTLPR) and irritable bowel syndrome: a meta-analysis of 25 studies. BMC Gastroenterol 2014;14:23.

47. Cremon C, Carini G, Wang B, et al. Intestinal serotonin release, sensory neuron activation, and abdominal pain in irritable bowel syndrome. Am J Gastroenterol 2011;106:1290-1298.

48. Tillisch K, Mayer EA, Labus JS. Quantitative meta-analysis identifies brain regions activated during rectal distension in irritable bowel syndrome. Gastroenterology 2011;140:91-100.

49. Aizawa E, Sato Y, Kochiyama T, et al. Altered cognitive function of prefrontal cortex during error feedback in patients with irritable bowel syndrome, based on FMRI and dynamic causal modeling. Gastroenterology 2012;143:1188-1198.

50. Xu F, Wu C, Guo F, et al. Transcriptomic analysis of Campylobacter jejuni NCTC 11168 in response to epinephrine and norepinephrine. Front Microbiol 2015;6:452.

51. Pigrau M, Rodiño-Janeiro BK, Casado-Bedmar M, et al. The joint power of sex and stress to modulate brain-gut-microbiota axis and intestinal barrier homeostasis: implications for irritable bowel syndrome. Neurogastroenterol Motil 2016;28:463-486.

52. Koloski NA, Jones M, Talley NJ. Evidence that independent gutto-brain and brain-to-gut pathways operate in the irritable bowel syndrome and functional dyspepsia: a 1-year population-based prospective study. Aliment Pharmacol Ther 2016;44:592-600.

53. Sykes MA, Blanchard EB, Lackner J, Keefer L, Krasner S. Psychopathology in irritable bowel syndrome: support for a psychophysiological model. J Behav Med 2003;26:361-372.

54. Barrett E, Ross RP, O’Toole PW, Fitzgerald GF, Stanton C. $\gamma$-Aminobutyric acid production by culturable bacteria from the human intestine. J Appl Microbiol 2012;113:411-417.

55. Saito YA, Petersen GM, Larson JJ, et al. Familial aggregation of irritable bowel syndrome: a family case-control study. Am J Gastroenterol 2010;105:833-841.

56. Beyder A, Mazzone A, Strege PR, et al. Loss-of-function of the voltage-gated sodium channel NaV1.5 (channelopathies) in patients with irritable bowel syndrome. Gastroenterology 2014;146:1659-1668.

57. Locke GR $3^{\text {rd }}$, Ackerman MJ, Zinsmeister AR, Thapa P, Farrugia G. Gastrointestinal symptoms in families of patients with an SCN5A-encoded cardiac channelopathy: evidence of an intestinal channelopathy. Am J Gastroenterol 2006;101:1299-1304.

58. Henström M, Diekmann L, Bonfiglio F, et al. Functional variants in the sucrase-isomaltase gene associate with increased risk of irritable bowel syndrome. Gut 2018;67:263-270.

59. Bajor A, Törnblom H, Rudling M, Ung KA, Simrén M. Increased colonic bile acid exposure: a relevant factor for symptoms and treatment in IBS. Gut 2015;64:84-92.

60. Spiller R. Irritable bowel syndrome: new insights into symptom mechanisms and advances in treatment. F1000Res 2016;5.

61. Appleby RN, Walters JR. The role of bile acids in functional GI disorders. Neurogastroenterol Motil 2014;26:1057-1069.

62. Shin A, Camilleri M, Vijayvargiya P, et al. Bowel functions, fecal unconjugated primary and secondary bile acids, and colonic transit in patients with irritable bowel syndrome. Clin Gastroenterol Hepatol 2013;11:1270-1275.

63. Wong BS, Camilleri M, Carlson P, et al. Increased bile acid biosynthesis is associated with irritable bowel syndrome with diarrhea. Clin Gastroenterol Hepatol 2012;10:1009-1015.e3.

64. Camilleri M, Busciglio I, Acosta A, et al. Effect of increased bile acid synthesis or fecal excretion in irritable bowel syndromediarrhea. Am J Gastroenterol 2014;109:1621-1630.

65. Duboc H, Rainteau D, Rajca S, et al. Increase in fecal primary bile acids and dysbiosis in patients with diarrhea-predominant irritable bowel syndrome. Neurogastroenterol Motil2012;24:513-520, e246-7.

66. Qin J, Li R, Raes J, et al; MetaHIT Consortium. A human gut microbial gene catalogue established by metagenomic sequencing. Nature 2010;464:59-65.

67. Clemente JC, Ursell LK, Parfrey LW, Knight R. The impact of the gut microbiota on human health: an integrative view. Cell 2012;148:1258-1270.

68. Maukonen J, Saarela M. Human gut microbiota: does diet matter? Proc Nutr Soc 2015;74:23-36.

69. Casén C, Vebø HC, Sekelja M, et al. Deviations in human gut microbiota: a novel diagnostic test for determining dysbiosis in patients with IBS or IBD. Aliment Pharmacol Ther 2015;42:71-83.

70. Bhattarai Y, Muniz P DA, Kashyap PC. Irritable bowel syndrome: a gut microbiota-related disorder? Am J Physiol Gastrointest Liver Physiol 2017;312:G52-G62.

71. Tap J, Derrien M, Törnblom H, et al. Identification of an intestinal microbiota signature associated with severity of irritable bowel syndrome. Gastroenterology 2017;152:111-123.

72. Parkes GC, Rayment NB, Hudspith BN, et al. Distinct microbial populations exist in the mucosa-associated microbiota of subgroups of irritable bowel syndrome. Neurogastroenterol Motil 2012;24:31-39.

73. Jalanka-Tuovinen J, Salonen A, Nikkilä J, et al. Intestinal microbiota in healthy adults: temporal analysis reveals individual and common core and relation to intestinal symptoms. PLoS One 2011;6:e23035.

74. Ringel Y, Williams RE, Kalilani L, Cook SF. Prevalence, characteristics, and impact of bloating symptoms in patients with irritable bowel syndrome. Clin Gastroenterol Hepatol 2009;7:68-72.

75. Barba E, Burri E, Accarino A, et al. Abdominothoracic mechanisms of functional abdominal distension and correction by biofeedback. Gastroenterology 2015;148:732-739.

76. Drossman DA, Morris CB, Hu Y, et al. A prospective assessment of bowel habit in irritable bowel syndrome in women: defining an alternator. Gastroenterology 2005;128:580-589.

77. Enck P, Aziz Q, Barbara G, et al. Irritable bowel syndrome. Nat Rev Dis Primers 2016;2:16014.

78. Böhn L, Störsrud S, Törnblom H, Bengtsson U, Simrén M. Selfreported food-related gastrointestinal symptoms in IBS are common and associated with more severe symptoms and reduced quality of life. Am J Gastroenterol 2013;108:634-641.

79. Jerndal P, Ringström G, Agerforz P, et al. Gastrointestinal-specific anxiety: an important factor for severity of GI symptoms and quality of life in IBS. Neurogastroenterol Motil 2010;22:646-e179.

80. Sunderland R. Irritable bowel syndrome in adults: symptoms, treatment and management. Nurs Stand 2017;31:52-63. 
81. Pimentel M, Morales W, Rezaie A, et al. Development and validation of a biomarker for diarrhea-predominant irritable bowel syndrome in human subjects. PLoS One 2015;10:e0126438.

82. Stotzer PO, Abrahamsson H, Bajor A, et al. Are the definitions for chronic diarrhoea adequate? Evaluation of two different definitions in patients with chronic diarrhoea. United European Gastroenterol J 2015;3:381-386.

83. Menees SB, Powell C, Kurlander J, Goel A, Chey WD. A metaanalysis of the utility of C-reactive protein, erythrocyte sedimentation rate, fecal calprotectin, and fecal lactoferrin to exclude inflammatory bowel disease in adults with IBS. Am J Gastroenterol 2015;110:444-454.

84. Ford AC, Spiegel BM, Talley NJ, Moayyedi P. Small intestinal bacterial overgrowth in irritable bowel syndrome: systematic review and meta-analysis. Clin Gastroenterol Hepatol 2009;7:1279-1286.

85. Dickinson B, Surawicz CM. Infectious diarrhea: an overview. Curr Gastroenterol Rep 2014;16:399.

86. Quigley EM, Fried M, Gwee KA, et al; Review Team. World Gastroenterology Organisation Global Guidelines Irritable Bowel Syndrome: A Global Perspective Update September 2015. J Clin Gastroenterol 2016;50:704-713.

87. Money ME, Camilleri M. Review: Management of postprandial diarrhea syndrome. Am J Med 2012;125:538-544.

88. Vijayvargiya P, Camilleri M, Shin A, Saenger A. Methods for diagnosis of bile acid malabsorption in clinical practice. Clin Gastroenterol Hepatol 2013;11:1232-1239.

89. Cairns SR, Scholefield JH, Steele RJ, et al; Association of Coloproctology for Great Britain and Ireland. Guidelines for colorectal cancer screening and surveillance in moderate and high risk groups (update from 2002). Gut 2010;59:666-689.

90. Soh JS, Lee HJ, Jung KW, et al. The diagnostic value of a digital rectal examination compared with high-resolution anorectal manometry in patients with chronic constipation and fecal incontinence. Am J Gastroenterol 2015;110:1197-1204.

91. Sultan S, Malhotra A. Irritable bowel syndrome. Ann Intern Med 2017;166:ITC81-ITC96.

92. Brandt LJ, Chey WD, Foxx-Orenstein AE, et al; American College of Gastroenterology Task Force on Irritable Bowel Syndrome. An evidence-based position statement on the management of irritable bowel syndrome. Am J Gastroenterol 2009;104 Suppl 1:S1-S35.

93. Rex DK, Johnson DA, Anderson JC, Schoenfeld PS, Burke CA, Inadomi JM; American College of Gastroenterology. American College of Gastroenterology guidelines for colorectal cancer screening 2009 [corrected]. Am J Gastroenterol 2009;104:739-750.

94. Rana SV, Malik A. Breath tests and irritable bowel syndrome. World J Gastroenterol 2014;20:7587-7601.

95. Manning AP, Thompson WG, Heaton KW, Morris AF. Towards positive diagnosis of the irritable bowel. Br Med J 1978;2:653-654.

96. Whitehead WE, Palsson OS, Simrén M. Irritable bowel syndrome: what do the new Rome IV diagnostic guidelines mean for patient management? Expert Rev Gastroenterol Hepatol 2017;11:281283.

97. Palsson OS, Whitehead WE, van Tilburg MAL, et al. Development and validation of the Rome IV diagnostic questionnaire for adults. Gastroenterology 2016;150:1481-1491.

98. Drossman DA. Functional gastrointestinal disorders: history, pathophysiology, clinical features and Rome IV. Gastroenterology 2016;150:1262-1279.e2.

99. Ford AC, Marwaha A, Lim A, Moayyedi P. Systematic review and meta-analysis of the prevalence of irritable bowel syndrome in individuals with dyspepsia. Clin Gastroenterol Hepatol 2010;8:401-409.

100. Zhu Y, Zheng X, Cong Y, et al. Bloating and distention in irritable bowel syndrome: the role of gas production and visceral sensation after lactose ingestion in a population with lactase deficiency. Am J Gastroenterol 2013;108:1516-1525.

101. McKenzie YA, Bowyer RK, Leach H, et al; (IBS Dietetic Guideline Review Group on behalf of Gastroenterology Specialist Group of the British Dietetic Association). British Dietetic Association systematic review and evidence-based practice guidelines for the dietary management of irritable bowel syndrome in adults (2016 update). J Hum Nutr Diet 2016;29:549-575.

102. Ford AC, Moayyedi P, Chey WD, et al; ACG Task Force on Management of Irritable Bowel Syndrome. American College of Gastroenterology Monograph on Management of Irritable Bowel Syndrome. Am J Gastroenterol 2018;113:1-18.

103. Moayyedi P, Quigley EM, Lacy BE, et al. The effect of fiber supplementation on irritable bowel syndrome: a systematic review and meta-analysis. Am J Gastroenterol 2014;109:1367-1374.

104. Drossman DA, Chey WD, Johanson JF, et al. Clinical trial: lubiprostone in patients with constipation-associated irritable bowel syndrome-results of two randomized, placebo-controlled studies. Aliment Pharmacol Ther 2009;29:329-341.

105. Castro J, Harrington AM, Hughes PA, et al. Linaclotide inhibits colonic nociceptors and relieves abdominal pain via guanylate cyclase-Cand extracellular cyclic guanosine 3',5'-monophosphate. Gastroenterology 2013;145:1334-1346.e1-11.

106. Lembo AJ, Lacy BE, Zuckerman MJ, et al. Eluxadoline for irritable bowel syndrome with diarrhea. N Engl J Med 2016;374:242-253.

107. Ford AC, Talley NJ, Schoenfeld PS, Quigley EM, Moayyedi P. Efficacy of antidepressants and psychological therapies in irritable bowel syndrome: systematic review and meta-analysis. Gut 2009;58:367-378.

108. Johannesson E, Simrén M, Strid H, Bajor A, Sadik R. Physical activity improves symptoms in irritable bowel syndrome: a randomized controlled trial. Am J Gastroenterol 2011;106:915-922.

109. Tong K, Nicandro JP, Shringarpure R, Chuang E, Chang L. A 9-year evaluation of temporal trends in alosetron postmarketing safety under the risk management program. Therap Adv Gastroenterol 2013;6:344-357.

110. Chang L, Lembo A, Sultan S. American Gastroenterological Association Institute Technical Review on the pharmacological management of irritable bowel syndrome. Gastroenterology 2014;147:1149-1172.e2.

111. Khalif IL, Quigley EM, Makarchuk PA, Golovenko OV, Podmarenkova LF, Dzhanayev YA. Interactions between symptoms and motor and visceral sensory responses of irritable bowel syndrome patients to spasmolytics (antispasmodics). J Gastrointestin Liver Dis 2009;18:17-22.

112. Ruepert L, Quartero AO, de Wit NJ, van der Heijden GJ, Rubin G, Muris JW. Bulking agents, antispasmodics and antidepressants for the treatment of irritable bowel syndrome. Cochrane Database Syst Rev 2011;(8):CD003460.

113. Ford AC, Quigley EM, Lacy BE, et al. Effect of antidepressants and psychological therapies, including hypnotherapy, in irritable bowel syndrome: systematic review and meta-analysis. Am J Gastroenterol 2014;109:1350-1365.

114. Villoria A, Serra J, Azpiroz F, Malagelada JR. Physical activity and intestinal gas clearance in patients with bloating. Am J Gastroenterol 2006;101:2552-2557.

115. Brenner DM, Moeller MJ, Chey WD, Schoenfeld PS. The utility of probiotics in the treatment of irritable bowel syndrome: a systematic review. Am J Gastroenterol 2009;104:1033-1049; quiz 1050.

116. Shanahan F, Quigley EM. Manipulation of the microbiota for treatment of IBS and IBD-challenges and controversies. Gastroenterology 2014;146:1554-1563.

117. Sundin J, Öhman L, Simrén M. Understanding the gut microbiota 
in inflammatory and functional gastrointestinal diseases. Psychosom Med 2017;79:857-867.

118. Malikowski T, Khanna S, Pardi DS. Fecal microbiota transplantation for gastrointestinal disorders. Curr Opin Gastroenterol 2017;33:8-13.

119. Jiang ZD, Ajami NJ, Petrosino JF, et al. Randomised clinical trial: faecal microbiota transplantation for recurrent Clostridium difficile infection - fresh, or frozen, or lyophilised microbiota from a small pool of healthy donors delivered by colonoscopy. Aliment Pharmacol Ther 2017;45:899-908.

120. Rossen NG, MacDonald JK, de Vries EM, et al. Fecal microbiota transplantation as novel therapy in gastroenterology: a systematic review. World J Gastroenterol 2015;21:5359-5371.

121. Singh R, Nieuwdorp M, ten Berge IJ, Bemelman FJ, Geerlings SE. The potential beneficial role of faecal microbiota transplantation in diseases other than Clostridium difficile infection. Clin Microbiol Infect 2014;20:1119-1125.

122. Halkjær SI, Boolsen AW, Günther S, Christensen AH, Petersen AM. Can fecal microbiota transplantation cure irritable bowel syndrome? World J Gastroenterol 2017;23:4112-4120.

123. Kang DW, Adams JB, Gregory AC, et al. Microbiota transfer therapy alters gut ecosystem and improves gastrointestinal and autism symptoms: an open-label study. Microbiome 2017;5:10.

124. El-Salhy M, Mazzawi T. Fecal microbiota transplantation for managing irritable bowel syndrome. Expert Rev Gastroenterol Hepatol 2018;12:439-445.

125. Pinn DM, Aroniadis OC, Brandt LJ. Is fecal microbiota transplantation (FMT) an effective treatment for patients with functional gastrointestinal disorders (FGID)? Neurogastroenterol Motil 2015;27:19-29.

126. Cammarota G, Ianiro G, Tilg H, et al; European FMT Working Group. European consensus conference on faecal microbiota transplantation in clinical practice. Gut 2017;66:569-580.

127. Lee $\mathrm{CH}$, Steiner T, Petrof EO, et al. Frozen vs fresh fecal microbiota transplantation and clinical resolution of diarrhea in patients with recurrent Clostridium difficile infection: a randomized clinical trial. JAMA 2016;315:142-149.

128. Holvoet T, Joossens M, Wang J, et al. Assessment of faecal microbial transfer in irritable bowel syndrome with severe bloating. Gut 2017;66:980-982.

129. Mazzawi T, Lied GA, Sangnes DA, et al. The kinetics of gut microbial community composition in patients with irritable bowel syndrome following fecal microbiota transplantation. PLoS One 2018;13:e0194904. 